\title{
Non-Governmental Organizations and World Population Issues
}

JOUKO HULKKO, LL.M.

Managing Director

Väestöliitto, The Family Federation of Finland

Helsinki, Finland

\section{Legal foundation}

The 71st article of the Charter of the United Nations is the basis for cooperation between ECOSOC, the U.N. Economic and Social Council, and Non-Governmental Organizations, NGOs. According to the article, the Council may negotiate with international and, upon hearing the nations in question, national organizations concerning issues in the Council's field of activity.

ECOSOC had already granted consultative status to these organizations in 1946, and the most recent re-evaluation of the situation occurred on May 23, 1968 (Resolution 1296). Thus a formal relationship was created between an intergovernmental organ and private-law associations representing different interest groups and a system which had not existed earlier.

In order to be granted consultative status with ECOSOC, a NGO must fulfil certain conditions. Its aims must be in accordance with the spirit, goals and principles of the U.N. In addition, the NGO must have recognized international status in its field, democratically approved rules and a board of directors responsible for its activities. A substantial precondition is that the NGO has special expertise beneficial to the activities of ECOSOC or to an organ connected to these activities. It must represent a special group in several countries and it must not be based on an intergovernmental agreement.

There are three consultative statuses. The first (General Consultative Status, Category I) includes international organizations which function in several of ECOSOC's areas of responsibility, have a large membership representative of the most important population groups in several U.N. member states. The second group (Special Consultative Status, Category II) includes organizations internationally recognized in their field and representing special expertise focusing on a few of ECOSOC's areas of responsibility. The third category (those On the Roster) includes organizations which do not fulfil the above requirements, but which can be seen to provide ECOSOC or other U.N. organs occasionally with useful assistance. 
Organizations in the first and second categories have the right of initiative in their field of activity and they can send their representative to monitor ECOSOC General Assemblies.

A special Council Committee of Non-Governmental Organizations was founded in the Economic and Social Council on June 21, 1946. It now has 19 members evenly representing each continent. The committee's duties include preparing applications from organizations applying for consultative status, reading the four-year reports of these organizations and carrying out work requested by ECOSOC.

Cooperation between the U.N. and NGOs is facilitated by the U.N. Non-Governmental Liaison Service, which was established 24 years ago and which publishes the bimonthly Go Between magazine and the Round Up - circular. They contain U.N. news of interest to the NGOs, accounts of meetings and reports, statements, NGO achievements, information about new books and a calendar of events. The May 1997 Round Up was dedicated to the ECOSOC Population and Development Commission's February session, whose theme was international migration. The 1998 theme was health and mortality and themes for 1999 are population growth, structure and distribution in regard to permanent economic growth and sustained development.

\section{What are NGOs like?}

The ECOSOC report General Review of Arrangements for Consultations with NGOs of May 26, 1994 examines this issue. NGOs are non-profit, independent associations, whose members are citizens or civic organizations from one or several countries and whose activities are determined by its membership to satisfy the needs of the members or those of one or more fields of activity. Their forms of organization, fields of activity, actions and financing differ greatly from each other.

NGOs can be divided roughly into two groups. The first includes organizations whose aims and forms of activity are associated with societal aspirations, initiative or they endeavor to strengthen local self-sufficiency and self-reliance by encouraging participation and the attainment of skills. The second group is formed by associations, which have evolved from social movements, are institutions and focus on political and governmental changes.

The term NGO has been criticized for its negative tone and also because it is easily understood to mean antigovernmental. Other terms which have been used alongside NGO are voluntary agencies, private voluntary organizations and civic organizations.

The use of the abbreviation NGO is widespread and established in the use of the U.N. and many international associations and even in the organizations' own use. It will most likely remain a common term covering all associations other than those in the government sector, although originally the term NGO referred only to organizations with consultative status in ECOSOC. 


\section{IUSSP - The International Union for the Scientific Study of Population}

The International Union for the Scientific Study of Population, IUSSP, is an association of demographers which arose out of the enthusiasm engendered by the first world population conference held in Geneva August 29 - September 3, 1927. The population conference had 100 participants from 27 different countries. As a result of the conference a preparatory committee was set up to found an international organization, which would be free of all ideology and would focus on the scientific study of population issues. The founding meeting of the IUSSP was held at the invitation of the preparatory committee in Paris on July 5, 1928 and the Union's rules were approved. The goal of the IUSSP is to globally promote population study, exchange information among demographers and neighboring scientific fields and raise interest in population issues. Every four years it organizes a broad international demographic conference, as well as regional conferences and conferences with a given theme.

The Union has acted and continues to act in collaboration with many international associations. It has long held consultative status in ECOSOC, in UNESCO and in the Council of Europe. One of the Union's significant permanent achievements is the publication of a multilingual demographic dictionary in 1960. The Finnish version was published in 1962 (G. Fougstedt, J. Hyppölä, T. Purola and A. Strömmer). It has been revised occasionally as the need arises. This dictionary has promoted the internationalization of demography and strengthened the international nature of this scientific field. In 1996 the Union had 1,778 members from 117 nations, 21 of which were from Finland.

\section{IPPF - The International Planned Parenthood Federation}

In 1952 eight family planning organizations founded IPPF, the International Planned Parenthood Federation. Only one organization from each country can be a member. Väestöliitto, The Family Federation of Finland has been an associate member of IPPF since 1959 and a regular member since 1967. IPPF now has members in about 150 nations. It is the world's second largest association of volunteer organizations. It promotes sexual health and family planning. The focus of its activities is in the developing countries.

\section{Population Conferences}

In the following I will use population conferences to examine changes in the significance of NGOs and especially of IUSSP and IPPF in regard to world population issues. This examination is made possible by the membership of Väestöliitto in IPPF, my membership in IUSSP and my participating, as a member of the Finnish delegation, in the preparations for all U.N. population conferences as well as in the conferences themselves. 


\section{The 1974 Bucharest Population Conference}

Together with IUSSP and some other demographic associations, the U.N. had arranged a scientific-technical world population conference in Rome in 1954 and in Belgrade in 1965. In the U.N. attention had been drawn in 1957 to the then current population growth rate reaching the eight billion mark in the year 2000. FAO was concerned about the sufficiency of food supplies. Some Asian nations were concerned with the results of the population census of 1960 and demanded that the U.N. give technical aid to nations wanting to decrease their birth rate. At the U.N. Population Commission the representative from the U.S.A., Mr. William H. Draper, proposed that the next world population conference be arranged in the 1970s and that it be more an intergovernmental conference than a scientific one.

The Bucharest World Population Conference and the celebration of the year 1974 as a World Population Year was prepared in expert symposia, to which representatives of the scientific associations in the field were also invited, including representatives of IUSSP. Twenty-five experts participated in the Population and Development Symposium in Cairo on June 4-14, 1973.

In Honolulu on August 6-15, 1973 an equal number of experts gathered under the theme of population and the family. The symposium reports were background data for the conference. In the original official draft for the world population program there was hardly any mention of the position of women and the role of family planning. One organization helped and financed a Women's Population and Development Conference, which was held in February 1974 and in which noted women representatives from almost all of the civic organizations in the U.N. member states participated. The report of this conference was appended to the background documents of the official conference and its central recommendations were approved.

The scientific associations in the field of demography, IUSSP and university faculties were quite well represented in the preparations for and in the actual Bucharest Conference as experts and members in the national delegations. Family planning or civic organizations were still not in a very prominent position. The world's first political population conference had delegations from 137 states, 109 participating organizations as well as observers from international organizations. The total number of participants was about 3,500 .

A clash between two ideologies was clearly apparent at the population conference. The Western powers, with the U.S.A. in the lead, saw the limiting of population growth as a precondition for economic growth. The communist countries believed that economic growth in itself would solve the population problems. Also in opposing positions were the proponents of narrowly-defined family planning and those promoting a broader approach, according to whom the population issue is an fundamental part of social and economic development.

Conflicting viewpoints, often based on experience, were also found among the NGOs. They had supported and promoted family planning from many, sometimes highly different starting points and using different means of action. They spoke of responsible parenthood, improving the position of women and of how family planning is a basic human right (this idea was included 
in the so-called Tehran Declaration of 1968). In many nations, birth control was a sensitive and politically difficult issue. Therefore this question became a classical challenge and mission for the NGOs, an issue in which governments did not become involved until the political risk was diminished.

There were varying views also among the NGOs. Two main viewpoints were apparent, however. Some felt that funds directed to population programs were a waste. They should be directed to the industrialization and modernization of third world countries. These countries would then go through the same process of demographic transition as the industrialized nations and would achieve a balance between the birth rate and mortality. According to the other viewpoint, the poor countries had fallen into a population trap and development would not begin until population growth was restrained. Population programs were seen as an essential precondition for economic development.

Several parallel events were arranged in connection with the official population conference, with the permission of the organizers: an international youth population conference, a photography exhibit, a meeting with the press active in the population field, a computer demonstration and a colorful children's international drawing contest exhibit. Organizations with consultative status in ECOSOC arranged a parallel conference, The Population Tribune, which functioned as a forum for organizations and individuals interested in this issue. There were 1,400 participants. Of these, 300 were representatives of associations, which had been granted consultative status in ECOSOC. This was the beginning of a new form of activity: since then all world conferences organized by the U.N. have had a parallel unofficial meeting of civic associations.

In Bucharest a World Population Plan of Action was approved. Its greatest significance was that it set the framework for population-related world aid and national action. This was an important milestone concerning population issues, because it was the first political world population conference complete with all the accompanying political passion. The power struggles and compromises were a strange and new phenomenon to the representatives of science and the NGOs - terrifying, even. This was not what people were accustomed to, but it was a reality to which they had to adjust. It was important for the NGOs that the many-faceted population issue cannot be solved without the active participation of non-governmental organizations. NGOs are mentioned in a few sections of the World Population Plan. Nations are urged to use the support of organizations as much as possible ( $96 \S)$. International organizations are urged to coordinate their mutual activities and to cooperate with other organizations (106 §). Voluntary organizations should be encouraged to take an important role in disseminating population information, in participating in population programs and in sharing their experiences when planning and implementing programs.

It may have been flattering for the NGOs to be mentioned in the World Population Plan of Action. Many NGOs did see it accordingly and reacted with enthusiasm.

In the World Population Plan of Action there was more emphasis, however, on the significance of the NGOs in disseminating information than as an equal partner in population programs. At that time there were no independent civic organizations in the communist 
nations nor were they very common in the developing nations. In Bucharest international political realities determined the position of the NGOs.

\section{The World Population Conference in Mexico City, August 6-14, 1984}

On May 9, 1979 ECOSOC asked the U.N. Population Committee and other organs as well as key organizations about the possibility of holding a new world population conference. Reactions were favorable and on November 11, 1981 ECOSOC made the decision to arrange the conference. It was to be open to all nations and to some international associations. In May 1983 ECOSOC expanded the parties to be invited to include international organizations and some civic movements.

The World Population Plan of Action was a springboard for the activities of many organizations. Its principles and aims provided a basis for commitment and appeal. Additional information was furnished by the World Fertility Survey, which was begun in 1972. This was the largest research program in the history of social science and included 41 nations from the developing countries and 20 developed countries. Over 200,000 women were interviewed. The program was carried out by the International Statistical Institute together with IUSSP, with UNFPA and several nations providing the economic support. The results were published as country-specific reports and as a comparative report. The fertility survey provided a few developing countries with their first reliable estimates of the population situation and developmental trends. The research program was ended in 1984 . The fertility survey was very useful in the preparations for the Mexico Conference and to NGOs in their local grassroots activities. Among IPPF member organizations, several had developed the idea of adding supplementary services to promote family planning, such as health care, personal hygiene, sanitary issues, teaching literacy, economic enterprise and cooperative systems.

After the Bucharest Conference the activities of the NGOs had developed and they began to criticize the World Population Plan of Action. On the basis of their experiences, they stated, for example, that good family planning programs can decrease fertility at the national level, even if economic development did not occur.

Economic development fails often to improve the quality of life of individuals. The World Population Plan of Action should be based on new reasoning, used in popular participation in development. The plan should focus more on the input and capacity of organizations. They should be supported and cooperation with them concerning important issues should be intensified. NGOs were among the first to show that world population growth was more a result of the decline in mortality than a growth in fertility. They suggested, as did many other sectors, that fertility should be balanced with low mortality, environmental needs and natural resources.

The UNFPA report Inventory of Population Projects in Developing Countries is published annually and lists all the population projects carried out by the U.N., governments and organizations. The $1973 / 74$ Inventory mentions that 26 organizations had about 1,600 population projects in the developing countries, with 750 local organizations as partners. In the 1981/82 Inventory the corresponding figures are $86,4,000$ and 2,500. According to the same source, 
before the Bucharest Conference less than ten percent of family planning programs were included in other development programs, but in 1982 the number of joint programs had doubled.

Before the Mexico Conference about 120 governments demonstrated positive action in practice by providing family planning services and information. This figure had doubled since the Bucharest Conference. According to UNFPA's estimate, population issues would not have progressed as well as they did without the active participation of the NGOs. Organizations act freely based on principle and ideology, governments on the basis of estimates and calculations, where the time perspective is also quite short. In population issues it takes a long time, even generations, for the results of actions to appear.

Among the preparations for the Mexican Population Conference were four meetings of experts in early 1983. The themes were the same as in the Bucharest Conference and the meeting reports formed the background documents for the population conference. NGOs were represented in these preparations, but in addition, a special conference was arranged in Geneva for the NGOs on September 13-15, 1983, in which 200 representatives of 62 international and national organizations participated.

The main purpose of the population conference was to update the World Population Plan of Action approved in Bucharest. One of the approved recommendations was the positive trend, which had occurred in population development. Actions necessary for maintaining this desired developmental trend were supported and encouraged. Issues focusing on refugees, outmigration and internal migration were more prominent than before. The renewed program emphasized more clearly than before that family and local circumstances should be taken into consideration when planning and implementing programs. The proposal IPPF had drawn up and actively marketed at the conference to support civic organizations and value their input was included in the program after being introduced by China, India and some other countries. What was new and significant in regard to NGOs was that the recommendations for implementing the program included one pertaining specifically to them:

\section{Recommendation 84:}

"National non-governmental organizations are invited to continue, in accordance with national policies and laws, their pioneering work in opening up new paths and to respond quickly and flexibly to requests from Governments, intergovernmental and international nongovernmental organizations, as appropriate, for the further implementation of the World Population Plan of Action. Governments are urged, as appropriate, within the framework of national objectives, to encourage the innovative activities of non-governmental organizations and to draw upon their expertise, experience and resources in implementing national programmes. Donors are invited to increase their financial support to non-governmental organizations“.

Mexico City Declaration on Population and Development adopted unanimously in August 14,1984 , states in paragraph 21: "Non-governmental organizations have a continuing important role in the implementation of the World Population Plan of Action and deserve encouragement and support from Governments and international organizations". 
The NGOs arranged their own events parallel to the official conference, including the possibility to become acquainted with experiences in the social marketing of condoms. A new event was the opportunity provided by the local member organization of IPPF, MEXFAM, for conference participants to acquaint themselves with its fieldwork.

A total of 146 countries, 28 international intergovernmental organs and 158 organizations participated in the Mexican Population Conference.

ICPD, International Conference on Population and Development in Cairo, September $5-9,1994$

Associating population issues with a more extensive future framework of qualitatively good development for humankind, including nature, the built-up environment, the economy and energy, has been slow. In view of the international community the population conferences in Bucharest and Mexico were intermediate mileposts, which offered a natural opportunity for global examination, an exchange of experiences, information and thoughts and insight into a new starting point. Pressure toward solving the problems in the field of population was increased by the $45 \%$ increase in the world population between the Bucharest and the Cairo conferences and the troubling estimates of future population growth ( 7.5 billion by the year 2014).

A total of 179 national delegations with about 3,500 members participated in the ICPD. Among them were about 300 members of Parliament. The conference was monitored by 4,200 members of the media. The conference was a worldwide media event.

The ICPD was able to reap a crop which had been ripening for about twenty years: the population issue should be examined more deeply and versatilely as a question related to a larger whole and to the complexity of development. The strategy for setting aims changed. Instead of population aims, the Programme of Action unanimously approved at the Cairo conference emphasizes, more clearly than ever, the importance of meeting the needs of individuals women, men, youth. Instead of concentrating on family planning alone, of prime importance are the manifold issues associated with the promotion of sexual health-linked factors including family planning, decreasing mortality and improving the population's state of health, education and the position of women. The Programme of Action and its aims and financing needs extend to the year 2015. In order to accomplish these vast measures NGOs were included, which meant a definite strengthening of their position.

In a departure from previous population conferences, the central international organizations were allowed a short address at the General Assembly of the conference. The first among the NGOs to address the conference was IPPF General Secretary, Mr. Halfdan Mahler, who announced that his organization wholeheartedly supported the conference's aims and hoped that the Programme of Action would be approved in a spirit of ethical consensus.

At the beginning of the sector on the principles of the Programme of Action, it is noted that each state has the sovereign right in implementing the recommendations in the program to 
respect the different beliefs and ethical values people hold, their cultural backgrounds and human rights. Thus the actual implementation of the aims and recommendations of the Programme of Action depends on the weight governments in power and the people lend to the document. For organizations and interest groups the Programme of Action was a valuable document for promoting the aims it mentions, especially in nations, where the governments do not act according to the principles and aims of the program. For the governments of developed countries and for organizations in the population field, the Programme of Action also functions as a good guideline, especially when making decisions concerning population-related development aid.

The comprehensive approach of the Cairo Population and Development Conference is visible in the changed attitude toward NGOs. The collapse of the Soviet Union and the political events in Eastern Europe had a crucial impact on this change. Earlier no independent civic organizations existed in these countries. According to a permeating principle, organizations are mentioned in the Programme of Action at all applicable points and they have their own chapter, Chapter 15 , which treats the cooperation with the non-governmental sector for twenty paragraphs. It is noted in the introduction that all citizens and groups in a society have the right and duty to actively promote the goals of the program. The increase in the interest of the NGOs reflects the significant and rapid change in the relationship between governments and different organizations. In almost all countries new models of collaboration are evolving between these sectors, which has a positive influence on the implementation of the Programme of Action.

The program notes in quite some detail the kind of organizations involved with population issues whose information, skills and experience can especially be used to successfully promote the implementation of the program. These include organizations for sexual and reproductive health, family planning, women, immigrants and refugees. These organizations should be invited to participate in decision-making bodies at the local, national and international level, as well as in the U.N. system, in order to ensure the effective implementation, monitoring and evaluation of the program. Civic organizations are expected to be reliable in their actions, like governments, as well as being open in their services and evaluation procedures.

The goal of the program is to promote efficient cooperation between various sectors of government and different civic organizations when discussing and making decisions concerning the planning, implementation, coordination, monitoring and evaluation of population, development and environmental programs.

One recommendation is that governments and intergovernmental associations, respecting the self-determination of civic organizations, supplement the decision-making procedure by including them as members.

NGOs should have a key position in the national and international development process. It is especially emphasized that governments must ensure the important role of women's organizations and their participation in the planning and implementation of population and development programs. In order to facilitate the effective participation of NGOs, they should be provided with the necessary information and documents as well as with material resources, if necessary. Governments should include NGO representatives in national delegations participating in international meetings dealing with population and development issues. 
In contrast to the programs of action of the Bucharest and Mexico conferences, the Cairo Programme of Action has noted the significance of the profit-oriented sector for social and economic development. The goal of the program is to promote cooperation between governments, international organizations and the profit-oriented sector, and the role of the profitoriented sector in manufacturing and distributing reproductive health and family planning products and contraceptives as well as in the availability of services in this field.

It is recommended that governments, civic organizations and international organizations cooperate more effectively with the profit-oriented sector in regard to population and development programs and that they develop methods for exchanging information and experiences relating to reproductive health and family planning issues.

The best part of the Programme of Action approved in Cairo was that population issues are part of a broader strategy for improving well-being. One weakness is that there is too little focus on the open sector (industry, commerce, business). Other neglected areas were the benefits of demographic information and research results to business (business demography) and that coordinating family and work responsibilities is significant for both business profits and the family life of employees - having children, for example. This would be a natural form of collaboration. The private sector was granted a chapter of its own in the program, however, which I consider a significant improvement in scope and increase in resources.

\section{NGO Forum in Cairo}

A large sports center near the official conference site was reserved for associations and organizations involved with population issues. The corridors of this center were lined with the exhibits and stands of volunteer organizations and official institutions. The whole spectrum of information and viewpoints from the local level all the way to global population issues was on display. There were a total of 60 exhibitors, the most important of whom included UNFPA, the World Bank, WHO, UNICEF, ICO, IIASA, IUSSP, IPPF and the Statistical Center of Egypt.

A special planning committee has prepared the NGO Forum alongside the official conference program. UNFPA, the European Union, and the governments of Sweden, Norway and Denmark, among others, and several associations interested in the field had supported the effort financially. UNFPA encouraged organizations to participate in the conference by inviting all organizations and persons active in the field of population and development to the Forum. There were a total of 5,000 participants.

Thus the extensive preparation and, above all, the later implementation of the Population and Development Conference's goals among the citizens were ensured. In addition, this brought the field of population an abundance of resources based on volunteerism and local expertise and a broad network well-immersed in this issue. 


\section{IPPF}

IPPF was very well prepared for the conference. Already one year before the conference, the central organization sent its member organizations background data, its own carefully prepared statements and preparatory conference documents. Thus IPPF was able to involve its entire member network in preparing for the ICPD at the national and international level. IPPF also had a direct link to the preparations, for Ghana's representative, Dr. Fred Sai, the chairperson of IPPF, was in a key position in the preparatory meeting of the conference and was the chairperson of the conference's main committee. The presentation given by General Secretary, Mr. Halfdan Mahler at the General Assembly of the conference was a success. IPPF provided the media efficiently with information both before and during the conference. It appeared daily in the conference publications The Earth Times and Terra Viva. Together with Egypt's family planning organization, IPPF arranged two visits for the media to family planning clinics in Cairo and the countryside. Over 50 key media participated in these visits, which helped representatives of the media to understand the purpose of the conference. In the NGO Forum IPPF and the Arab Region of IPPF had their own information desks.

The main IPPF presentations at the NGO Forum were the events "World Leaders State their Views" and "Religions and Population". The publicity attained by IPPF raised the image of the organization among expert associations doing family planning fieldwork. Over 200 representatives from IPPF member organizations were present and about 80 national delegations included representatives from family planning organizations. There were 28 member organization representatives from Europe, 18 of whom were members of their country's official delegation. IPPF financial backing made it possible for numerous countries, especially developing countries and countries in Eastern and Central Europe, to participate.

\section{IUSSP}

As the cooperative association of demographers, IUSSP was well prepared for this conference. IUSSP published four policy and research papers before the conference, in addition to which it gave a series of seven lectures at the NGO Forum. These lectures were available in booklet form. The lectures were well prepared, skilled and rewarding to the audience.

\section{From being present to becoming participants}

On the basis of the preparations, activities and Programme of Action of the Cairo conference, one can see that the international, national and even local NGOs have become important partners in the planning and implementation of social development. It was a political concession for governments to accept NGOs as more and more equal partners. The Programme of Action emphasizes the importance of NGOs and a civil society, in general, more clearly than any previous U.N. meeting. The term civil society is used to describe different non- 
governmental groups such as NGOs, businesses, foundations, the media and various grassroots level citizens' movements. NGOs are registered, legally organized associations - part of the civil society.

The trust governments have in the quality and effectiveness of the work NGOs do has increased. In developing countries NGOs act more and more as the implementers or participants in development programs. Compared to governments, NGOs often have functional prerequisites: flexibility, being unofficial, local awareness and their members' high involvement with given tasks and aims.

The background paper (A Five-Year Review of Progress towards the Implementation of the Programme of Action of the International Conference on Population and Development) prepared by UNFPA for the Hague Forum on February 8-12, 1999 gives a good picture of the new partnership between governments and NGO community groups in the implementation, coordination and evaluation of population policies and programs. According to the paper, NGOs have had an important role in every continent of the world and special emphasis is placed on the leading role of IPPF and women's NGOs in the activities of the civil society. UNFPA has been determined in strengthening cooperation with NGOs in implementing the Cairo Programme of Action. In 1995 UNFPA founded a special NGO Advisory Committee, which has representatives from international, regional, national and local organizations. The committee has made many proposals for developing cooperation between UNFPA and NGOs. For example, on its initiative the UNFPA Executive Board agreed to invite selected NGOs to participate in its deliberations.

NGOs have participated actively in monitoring the Cairo conference and they have been provided more opportunities for this than ever before. Following are a few examples:

- ECE Review of Population and Development, December 7-12, 1999, Budapest, Hungary.

- UNFPA and IPPF signed an agreement in July 1996 to cooperate in implementing the Cairo Programme of Action.

- European Roundtable on ICPD +5, the Role of Civil Society in Implementing the Cairo Programme of Action, December 21-22, 1999, Brussels, Belgium.

- Cairo +5, The Hague, Parliamentarians Forum, February 4-5, NGO Forum and Youth Forum 6-8, before official International Forum, 8-12, 1999.

- U.N. Commission on Population and Development, March 22-30, 1999, New York.

A widely distributed letter invited NGOs to participate in the ECOSOC NGO Section at the end of the year.

The Youth Forum in the Hague was a historic achievement. It was organized by the World Population Foundation in collaboration with UNFPA. The Forum brought together $13215-$ 24-year-old people from 111 countries. At the end of the meeting the report of the Forum was adopted by the majority defined as being $60 \%$ of the participants. 
Civil societies - however they are understood in various nations - and especially NGOs, with IPPF at the forefront, have enthusiastically and sincerely accepted the offer to participate provided in the Cairo Programme of Action. They have been the most eager advocates of the aims of the Programme of Action, distributed information, arranged services and been its active proponents in contacting governments. NGOs have learned better ways of cooperating together and with governments and have developed sexual health and family planning services, which are well-suited to local circumstances. The economic aims of implementing the Cairo Programme of Action have not been reached. This is also apparent in the NGOs' economic possibilities to train their personnel, acquire necessary material and equipment, contraceptives etc. Their strength is often in their very highly professional volunteer workers, the significance of whose input is quite difficult to measure.

To IUSSP the fact that also other organizations have become active in population matters probably has become as a surprise. In the Cairo +5 Review process IUSSP was invisible and produced only the Science Policy Statement. The object of the statement is to emphasize the importance of population studies as the foundation of international politics and to inform about IUSSP's plans for the years 1999-2003. In it two facts are stated: "Cairo Programme of Action paid less attention to the demographic, economic and sustainable human development unifications of these policies" and "the scientific community as such was submerged under a myriad of NGOs“. Demography should prove that it is needed and that it is able to spread the results of science in an understandable way. 